44

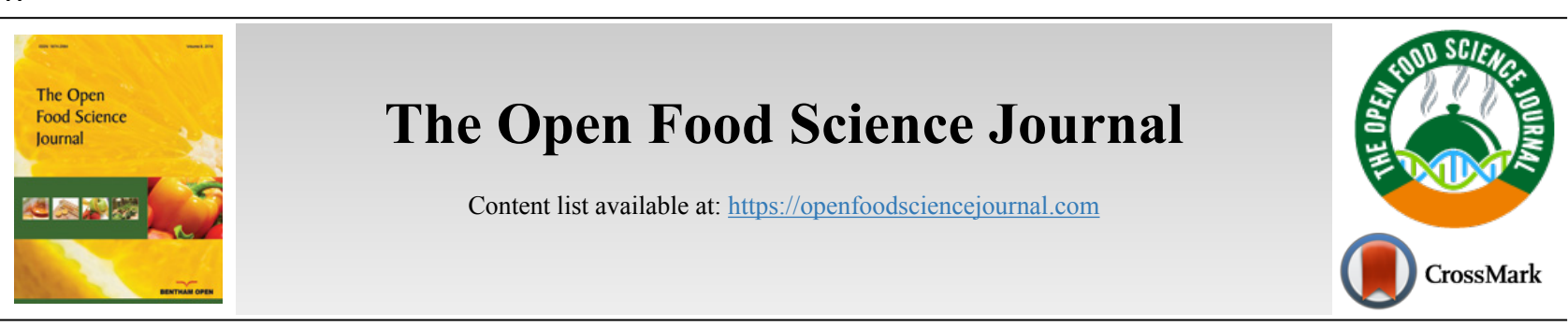

RESEARCH ARTICLE

\title{
Sensory and Composition Analyses of the Aqueous Phases from the Concentration of Guava (Psidium Guava L.) and Mango (Mangifera Indica L.) Juices and the Process-Induced Losses of Vitamin C
}

Renata B. Bodini ${ }^{1}$, Evandro M. Montini ${ }^{1}$, Carolina C. de Carvalho ${ }^{2}$, Luiz A. B. de Moraes ${ }^{3}$, Antonio J. de A. Meirelles ${ }^{4}$ and Alessandra L. de Oliveira,

${ }^{1}$ Faculty of Animal Science and Food Engineering (FZEA), University of São Paulo, Av. Duque de Caxias Norte, 225, Pirassununga, SP, CEP 13635-900, Brazil

${ }^{2}$ Center of Engineering, Modeling and Applied Social Sciences (CECS), Federal University of ABC, Alameda da Universidade $s / n^{o}$, São Bernardo do Campo, SP, CEP 09606-045, Brazil

${ }^{3}$ Faculty of Philosophy Sciences and Letters of Ribeirão Preto, (FFCLRP), University of São Paulo, Av. Bandeirantes, 3900, Ribeirão Preto, SP, CEP 14040-901, Brazil

${ }^{4}$ Faculty of Food Engineering (FEA), State University of Campinas, R. Josué de Castro, S/N - Cidade Universitária, Campinas, SP, Brazil

\begin{abstract}
:
Introduction:

One of the major problems in the juice industry is the loss of the fruit aroma during the thermal concentration techniques. During this process, the water evaporation, which carries the volatiles, compromises the juice's flavor. In the fruit juice concentration by vacuum evaporation, the aqueous fraction with the volatiles is composed of only one phase.

Methods:

This study analyses the volatiles of the aqueous fractions from the concentration of mango and guava juices in a vacuum evaporator under different temperatures. The volatiles from the aqueous fractions were analyzed using mass spectrometry and the sensorial analysis evaluated the fruit aroma intensity.

Results:

Eighteen volatiles were identified in mango juice, among them, monoterpenes, sesquiterpenes and ketones were the major ones. The major compounds found in both mango juice and its aqueous fractions were 3 -carene, $\beta$-pinene, $\beta$-terpinene and limonene. In the volatile profile of the aqueous fraction from the guava juice, the predominant compounds were aldehydes, such as $n$-hexanal and, the alcohol eucalyptol. 24 compounds were identified, including alcohols, sesquiterpenes, esters and ketones, and all characteristic volatiles were present in the guava fruit. Under the different temperature and vacuum conditions, the loss of vitamin $\mathrm{C}$ ranged from 35 to $77 \%$ for mango and from 15 to $55 \%$ for guava juices.

Conclusion:

Aqueous fractions collected early in the concentration under different temperatures were richer in the distinctive fruit odor when compared with the fractions collected at the end of the process. The loss of vitamin $\mathrm{C}$ was higher at higher temperatures and vacuum applied.
\end{abstract}

Keywords: Mango, Guava, Aroma, Concentrated juice, Hydrolates, Aqueous fractions.

\begin{tabular}{l|l|l|l} 
Article History & Received: January 14, 2019 & Revised: February 20, 2019 & Accepted: March 06, 2019
\end{tabular}

\section{INTRODUCTION}

Concentrated fruit juices are those obtained from fresh

* Address correspondence to this author at the Faculty of Animal Science and Food Engineering (FZEA), University of São Paulo, Av. Duque de Caxias Norte, 225, Pirassununga, SP, CEP 13635-900, Brazil; Tel: +55 1935654268; E-mail: alelopes@usp.br juices through the extraction of water, and when reconstituted, they must present characteristics of a fresh juice [1]. Concentrated juices are widely used industrially as ingredients in products, such as ice creams, jellies and fruit juices. The low water activity of concentrated juices also provides higher microbiological stability than whole juices, as well as reduces 
the packaging, storage and transport costs [2].

The evaporation process is one of the main methods of fruit juice concentration. However, this practice causes losses of most of the aromatic compounds responsible for the aroma and flavor, leading to a decline in the sensorial quality of the final product $[2,3]$. To maintain the nutrient content, and the natural aroma and flavor of the fruit juices, the evaporation process must be carried out at low temperature and low pressure [4]. In the food industry, vacuum concentration, with reduction of the boiling temperature [1] and the use of an aroma recovery unit [5], aim to minimize these changes. The volatile compounds evaporated together with the water in the concentration process can be recovered by condensation of the aqueous fraction (fruit juice hydrolates), and added back into the juice to achieve the characteristic aroma and flavor of the fruits [6].

Mango (Mangifera indica L.) and guava (Psidium guajava L.) are examples of very nutritious tropical fruits, of great commercial interest in Brazil and used industrially in the production of concentrated juices. The mango fruit is rich in vitamin $C$, with values of $43-110 \mathrm{mg} / 100 \mathrm{~g}$, depending on the variety and degree of maturation [7]. Guava is also an excellent source of vitamin C (50-300 mg/100 g fruit), besides niacin, riboflavin and vitamin A $[8,9]$.

The nutritional losses in the mango and guava juices caused by the concentration process are mainly represented by the oxidation of vitamin $\mathrm{C}$, producing compounds with carbonyl radicals that react with amino groups, and by polymerization, which produces dark pigments that are responsible for the darkening of the juices that contain ascorbic acid [3]. Therefore, it is necessary to evaluate the effect of the concentration process on the changes in ascorbic acid content since vitamin $\mathrm{C}$ is unstable in the presence of light, oxygen and elevated temperatures [3].

Aroma is a complex mixture of a wide range of organic compounds, such as alcohols, aldehydes, ketones, esters, lactones, terpenes, carboxylic acids, hydrocarbons, amines, mercaptans, ethers, phenols and lactones [10, 11]. While all of the present compounds contribute to the general aroma of the fruit or juice, some specific compounds contribute a particular characteristic [12].

Terpene hydrocarbons represent the main class of volatile compounds in mango, and $\delta$-3-carene is a major contributor to the typical mango aroma. The components limonene, $\beta$ ocimene, myrcene and $\alpha$-terpinolene also stand out in some mango varieties [13, 14]. Sakho [15] identified sesquiterpenes, esters and, mostly, monoterpenes in mango. Pandit et al. [16] detected 84 volatile compounds in 27 mango varieties and noticed that $\alpha$-pinene, $\beta$-myrcene and $\beta$-caryophyllene were present in all varieties. The same authors concluded that the aroma and flavor of the mango were attributed mainly to the terpene hydrocarbons.

Guavas have a strong, unique and attractive flavor and aroma, due to the presence of esters and terpenes [17]. The volatile compounds present in guavas include aldehydes, such as (E)-2-hexenal and (Z)-3-hexenal, esters ( $(E)$-3-hexenyl acetate, (Z)-3-hexenyl acetate, ethyl hexanoate and ethyl butanoate), 1,8-cineole, monoterpenes (myrcene and limonene) and the sesquiterpenes caryophyllene, $\alpha$-humulene and $\beta$-bisabolene $[17,8,18]$.

The compounds responsible for the aroma and flavor of fruits differ in their boiling points, molecular structure and solubility, so it is highly challenging to separate these components using one recovery procedure [19]. Consequently, each juice requires specific evaporation conditions and characterization of the aromatic composition in each recovered fruit juice hydrolates, to optimize the aroma recovery process, considering only aqueous fractions that present the most representative volatile compounds of the studied fruit $[19,20]$. According to Ramteke et al. [19], 30\% of the condensed aqueous fraction from the mango juice concentration, presents $90 \%$ of the juice's volatile aromatic compounds.

Considering the importance of the concentrated juices production in the Brazilian market, this study aimed to identify which condensed aqueous fractions, acquired under different evaporation concentration conditions (pressure, temperature and time), presented most of the volatile aromatics representative of mango and guava juices. The main aqueous fraction of each juice was selected sensorially by trained tasters, and analyzed by Gas Chromatography Coupled to Mass Spectrometry (GC/MS), an important tool in the study of aroma composition. The findings are expected to direct and optimize the process of recovery of aromas in concentrated juices, enabling products with improved sensorial quality.

The classical thermal concentration of fruit juice is a very well developed conservation technique, but the maintenance of the quality of these concentrated juices has still been research subjects, mainly the concentration processes of aroma from the aqueous phase (hydrolates). There is particular attention to hydrolates from apple juice concentration [21, 22], but there are no scientific reports on the aromatic compounds of mango and guava that migrate to the aqueous phase during the process. This research makes possible to know the aroma of tropical fruit juices that migrates to the hydrolates of the thermal concentration processes, first stage so that these can be recovered later.

\section{EXPERIMENTAL}

\subsection{Sample Preparation}

The guava ( $P$. guajava L.) and Tommy Atkins mango ( $M$. indica L.) fruits were obtained from regional supply stations, selected for the same maturation period, hygienized, cut and stored in a freezer at $-18{ }^{\circ} \mathrm{C}$. The juices were prepared by homogenizing $200 \mathrm{~mL}$ of deionized water per $100 \mathrm{~g}$ of fruit in a blender for $5 \mathrm{~min}$.

Mango and guava juices were analyzed for the soluble solids concentration $\left({ }^{\circ}\right.$ Brix), using an Abbe refractometer (Lambda 2WAJ, Atto Instruments Co.). The vitamin $\mathrm{C}$ concentration in the juices was determined by the reduction of ascorbic acid with 2,6-Dichlorophenolindophenol [23]. 
Table 1. Intensity of the characteristic aroma of guava and mango in the different aqueous fractions resulting from the juice concentration process.

\begin{tabular}{|c|c|c|c|c|c|c|}
\hline Assay & \begin{tabular}{|l|} 
Vacuum \\
(mmHg)
\end{tabular} & Temperature $\left({ }^{\circ} \mathrm{C}\right)$ & Fractions & Collection Interval (min) & \begin{tabular}{|c|}
$\begin{array}{c}\text { Aroma Intensity } \\
\text { Mango }\end{array}$ \\
\end{tabular} & $\begin{array}{c}\text { Aroma Intensity } \\
\text { Guava }\end{array}$ \\
\hline \multirow{3}{*}{1} & \multirow{3}{*}{650} & \multirow{3}{*}{50} & 1 & 15 & $6.52^{\mathrm{a}}$ & $5.93^{\mathrm{a}}$ \\
\hline & & & 2 & 30 & $5.22^{\mathrm{a}}$ & $3.79^{\mathrm{a}, \mathrm{b}}$ \\
\hline & & & 3 & 45 & $3.14^{\mathrm{b}}$ & $2.97^{\mathrm{b}}$ \\
\hline \multirow{3}{*}{2} & \multirow{3}{*}{650} & \multirow{3}{*}{55} & 1 & 15 & $6.01^{\mathrm{a}}$ & $6.69^{\mathrm{a}}$ \\
\hline & & & 2 & 30 & $5.52^{\mathrm{a}}$ & $4.03^{\mathrm{b}}$ \\
\hline & & & 3 & 45 & $2.48^{\mathrm{b}}$ & $0.97^{\circ}$ \\
\hline \multirow{3}{*}{3} & \multirow{3}{*}{650} & \multirow{3}{*}{65} & 1 & 15 & $6.50^{\mathrm{a}}$ & $6.78^{\mathrm{a}}$ \\
\hline & & & 2 & 30 & $5.45^{\mathrm{a}}$ & $3.86^{\mathrm{b}}$ \\
\hline & & & 3 & 45 & $2.90^{\mathrm{b}}$ & $2.00^{\mathrm{c}}$ \\
\hline \multirow{3}{*}{4} & \multirow{3}{*}{680} & \multirow{3}{*}{45} & 1 & 20 & $6.02^{\mathrm{a}}$ & $5.48^{\mathrm{a}}$ \\
\hline & & & 2 & 40 & $2.53^{\mathrm{b}}$ & $3.58^{\mathrm{a}, \mathrm{b}}$ \\
\hline & & & 3 & 60 & $1.83^{\mathrm{bc}}$ & $2.36^{\mathrm{b}}$ \\
\hline \multirow{3}{*}{5} & \multirow{3}{*}{680} & \multirow{3}{*}{50} & 1 & 15 & $5.87^{\mathrm{a}}$ & $7.01^{\mathrm{a}}$ \\
\hline & & & 2 & 30 & $4.49^{\mathrm{a}}$ & $1.54^{\mathrm{b}}$ \\
\hline & & & 3 & 45 & $1.76^{\mathrm{b}}$ & $0.84^{\mathrm{b}}$ \\
\hline \multirow{3}{*}{6} & \multirow{3}{*}{680} & \multirow{3}{*}{55} & 1 & 15 & $5.84^{\mathrm{a}}$ & $6.74^{\mathrm{a}}$ \\
\hline & & & 2 & 30 & $3.20^{\mathrm{b}}$ & $1.92^{\mathrm{b}}$ \\
\hline & & & 3 & 45 & $1.12^{\mathrm{c}}$ & $0.82^{\mathrm{b}}$ \\
\hline \multirow{3}{*}{7} & \multirow{3}{*}{680} & \multirow{3}{*}{65} & 1 & 10 & $5.26^{\mathrm{a}}$ & $7.50^{\mathrm{a}}$ \\
\hline & & & 2 & 20 & $3.69^{\mathrm{ab}}$ & $3.81^{b}$ \\
\hline & & & 3 & 30 & $1.84^{\mathrm{b}}$ & $1.44^{\mathrm{b}}$ \\
\hline
\end{tabular}

*Tukey mean with different letters in the same column differed significantly at the $\mathrm{p} \leq 0.05$ level for the same assay.

Name:

Date:_L__ I

Please evaluate the intensity of the characteristic aroma of the fruit (guava or mango) in the coded sample and express your impression using the scale below.

\section{Sample}

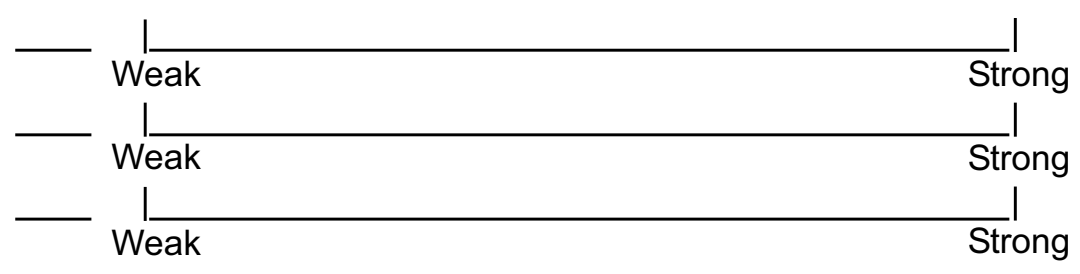

\section{Commentaries:}

Fig. (1). Sensory evaluation card of unstructured scale of $9 \mathrm{~cm}$.

\subsection{Juices Concentration and their Aqueous Fraction}

The homogenized, sieved and standardized juices $\left(4^{\circ} \mathrm{Brix}\right)$ were concentrated on a rotary evaporator (Yamato RE-41, JP) under temperature and vacuum conditions (Table 1) based on industrial evaporators and the experimental settings used by Martini [1]. The concentration process was stopped when the desired concentration of soluble solids ( ${ }^{\circ}$ Brix) was reached. This value was considered as $11^{\circ}$ Brix, based on the soluble 
solids content of commercially-available concentrates and pasteurized juices.

The time of concentration required to retrieve the aqueous fractions was determined from preliminary tests, and depended on the process conditions. The sampling was done at three different times, according to the trial design adopted in Table $\mathbf{1}$. These fractions were sensorially analyzed to verify the different intensity levels of the characteristic aroma of the fruit present.

\subsection{Sensory Analysis}

The sensory tests were undertaken at the Sensory Analysis Laboratory of the Department of Food Engineering (ZEA), in compliance with Resolution 196/96 of the Ministry of Health, and approved by the EERP/USP Research Ethics Committee under protocol number 0766/2007. These analyses were used as a tool to verify the intensity of the characteristic aroma of mango and guava, respectively, in the different aqueous fractions collected during the juice concentration, and thereby identify which of the fractions would be significant regarding the aroma intensity characteristic of the fruit. The tasting panel, composed of students and staff over the age of 18 years, was selected and trained as described in section 2.3.1.

\subsubsection{Tasters Selection}

The triangular discriminative test was used to select tasters with the ability to recognize differences in the flavor intensity of beverages. The samples consisted of commercial strawberry aroma solutions $\left(502223 \mathrm{C}\right.$, Firmenich $\left.{ }^{\circledR}\right)$ at two concentrations ( 2.5 and $5.0 \mathrm{~mL}$ of aroma in $1 \mathrm{~L}$ distilled water, respectively). The test was performed in individual booths under fluorescent light. Each tester received three samples (two equal and one different) and was instructed to indicate on the analysis chart, the different sample from the three presented. The samples, coded with a three-digit number according to a complete block diagram, were served in capped tulip-type cups. The testers were asked to smell the solutions when removing the cap after slow stirring. The selected sensory team was composed only by the testers who were able to identify the difference in aroma intensity among the samples, with at least $75 \%$ of correct answers in the four repetitions given.

\subsubsection{Tasters Training}

Mango and guava juices, respectively, were presented to the selected tasters at two different concentrations, to develop and train their olfactory memory in relation to the strong and weak intensity of the aromas, characteristic of these fruits. The two intensities offered were strong $(200 \mathrm{~mL}$ water to $100 \mathrm{~g}$ fruit) and weak $(50 \mathrm{~mL}$ of the above prepared juice diluted in $200 \mathrm{~mL}$ distilled water), and corresponded to the extremes of the $9 \mathrm{~cm}$ unstructured hedonic scale (Fig. 1).

\subsubsection{Sensory Analysis of the Aqueous Fraction}

The trained tasters were instructed to evaluate the aroma intensity characteristic of the aqueous fractions collected during the juice concentration process (Table 1), by indicating the intensity of the characteristic aroma of mango and guava in each fraction on a $9 \mathrm{~cm}$ unstructured scale (section 2.3.2; Fig.
1). The samples were composed of absorbent paper strips containing an aliquot $(0.1 \mathrm{~mL})$ of each analyzed aqueous fraction. The strips were coded with three-digit numbers and evaluated in individual booths.

The form of presentation was monadic and randomized according to a complete block diagram, to avoid first-order effects $[24,25]$. The time between the application of the aliquot of the aqueous fraction on the paper tape and the presentation to the tester was duly standardized. The testers assessed each of the samples in three replicates.

\subsection{Analysis of the Aqueous Fraction Composition}

The volatile compounds present in the aqueous fractions derived from the concentration of mango and guava juices, respectively, were trapped on Porapak-Q (80-100 mesh; Waters Corporation, USA) packed into a glass column $(0.5 \mathrm{~cm}$ internal diameter $\times 50 \mathrm{~mm}$ long) enclosed with glass wool at the ends, using an adaptation of the method proposed by Franco \& Rodrigues-Amaya [26] and Oliveira et al. [27]. The aqueous fraction resulting from the total concentration period of each juice was transferred to a volumetric flask that was connected to the Porapak-Q trap under a constant vacuum of 15 psi. The trapped volatiles were eluted from the Porapak-Q after $3 \mathrm{~h}$, using $2 \mathrm{~mL}$ of pure ethyl acetate (Mallinckrodt, USA) and analyzed by GC/MS (Shimadzu GC 2010 Plus) at the Chemistry Department of FFCLRP-USP.

The GC/MS apparatus was equipped with a split/split-less injector maintained at $250{ }^{\circ} \mathrm{C}$, which was used to introduce the sample ( $2 \mu \mathrm{L}$ injection volume). Separation was achieved on a BP1 capillary column $(30 \mathrm{~m} \times 0.25 \mathrm{~mm} \times 0.25 \mathrm{~mm})$ at an internal pressure of $15 \mathrm{psi}$ with helium as the carrier gas, and a temperature programmed ramp from $50{ }^{\circ} \mathrm{C}(2 \mathrm{~min})$ to $180^{\circ} \mathrm{C}$ at $4{ }^{\circ} \mathrm{C} / \mathrm{min}$. The detector temperature was $280{ }^{\circ} \mathrm{C}$, and the mass spectrum was acquired from 50 to $600 \mathrm{~m} / \mathrm{z}$. The electron ionization energy was $70 \mathrm{eV}$. Retention rates were determined by analyzing a standard mixture of a homologous series of $n$ alkanes $\left(\mathrm{C}_{9}-\mathrm{C}_{25}\right)$, prepared in ethyl acetate, to give the Kovats index under the same chromatographic conditions used in separating the volatiles present in the sample. Preliminary identification of the volatile components of the juices was based on the comparison of the spectra obtained experimentally with those from the NIST62.LIB mass spectral library.

The Kovats index was calculated according to Eq. (1):

$$
\text { Kovats index }=100 z+100\left[\frac{\log t^{\prime} R_{x}-\log t^{\prime} R_{Z}}{\log t^{\prime} R_{(z+1)}-\log t^{\prime} R_{Z}}\right]
$$

where $t^{\prime} R_{x}$ is the retention time adjusted to compound $x$, and $t^{\prime} R_{z}$ and $t^{\prime} R_{(z+1)}$ are the retention times adjusted for normal chain alkanes, where $t^{\prime} R_{x}$ is intermediate to $t^{\prime} R_{z}$ and $t^{\prime} R_{(z+1)}$.

\section{RESULTS AND DISCUSSION}

\subsection{Sensory Analysis}

\subsubsection{Selection and Training of Tasters}

The testers who had at least $75 \%$ of correct answers in the triangular discriminative test were selected as the sensory team. 

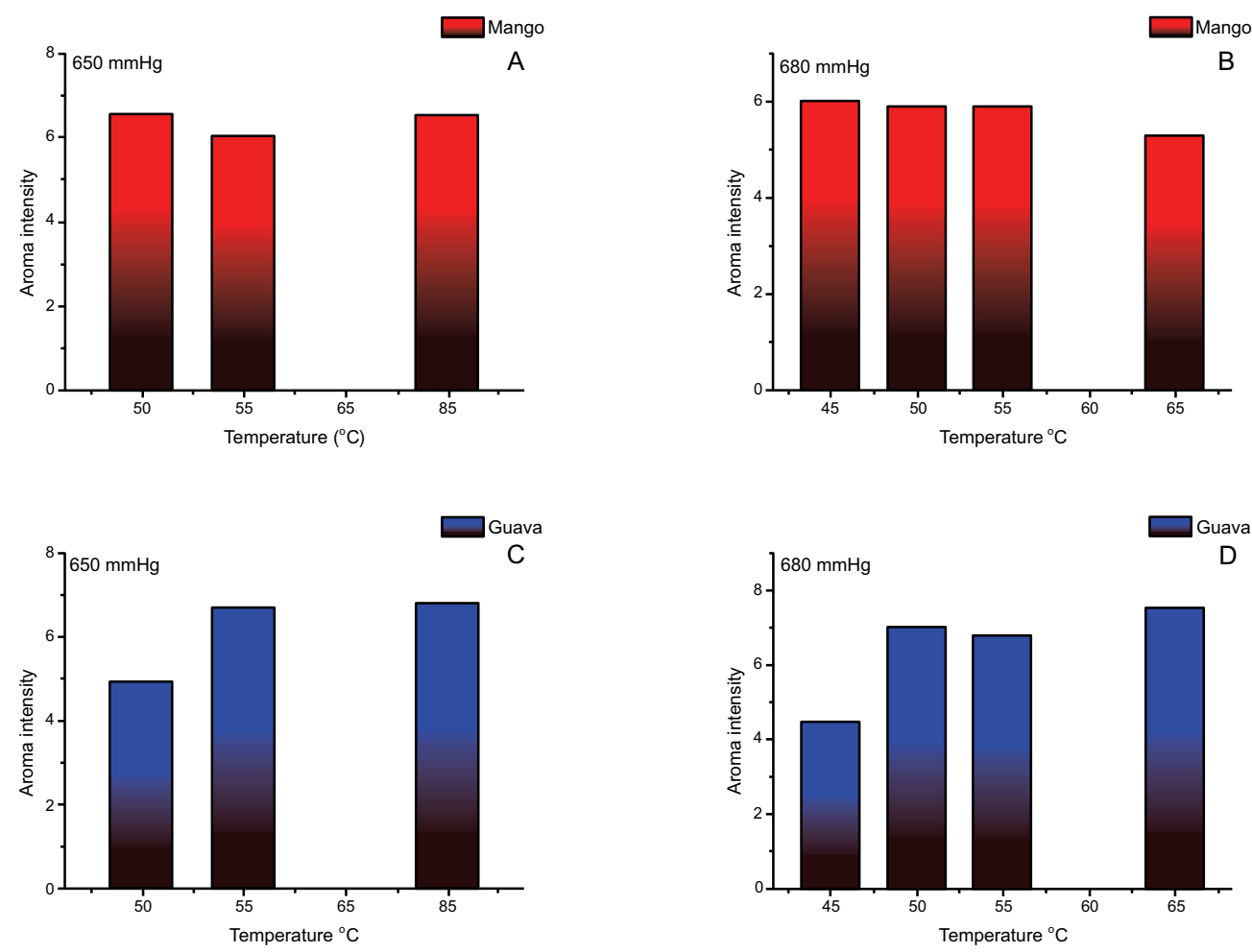

Fig. (2). Intensity of characteristic mango aroma of (A: $650 \mathrm{mmHg}$ and B: $680 \mathrm{mmHg}$ ) and guava (C: $650 \mathrm{mmHg}$ and D: $680 \mathrm{mmHg}$ ) in the aqueous fractions of the first collection made in different temperature conditions.

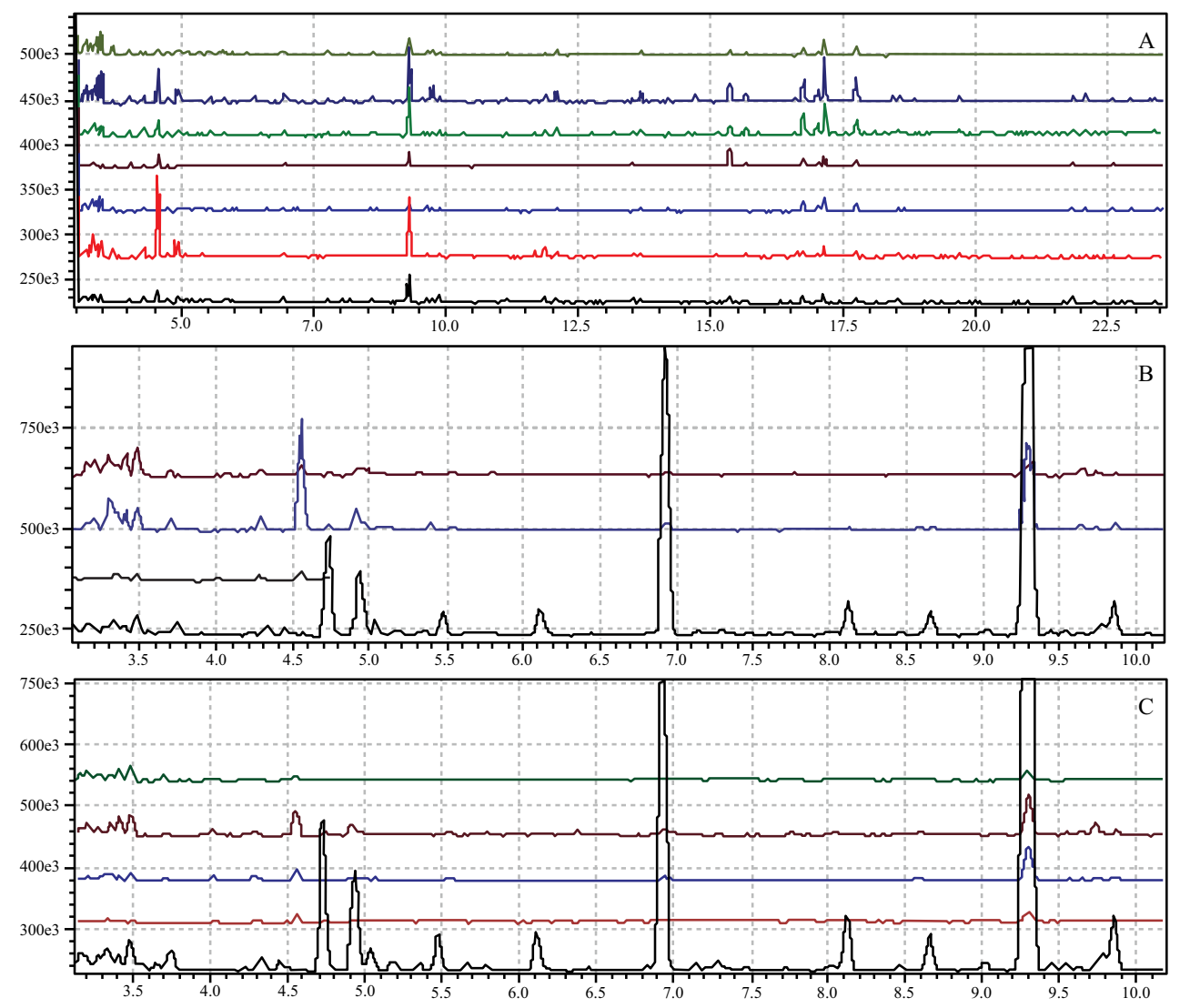

Fig. (3). (A) Comparison of the TIC of the assays $1-, 2-, 3-, 4-, 5-, 6-, 7-$; (B) natural juice -, tests $1-, 2-, 3-$; (C) natural juice -, tests $4-, 5-, 6-, 7-$ 
Among the 120 testers participating in the selection process, only 12 were chosen. Of these, 2 were $100 \%$ correct, and 10 were $75 \%$ correct, and 11 evaluated the intensity of the mango and guava aromas in the aqueous fractions of the juices.

\subsubsection{Intensity of Aroma of Aqueous Fractions}

Table 1 presents the intensity of the characteristic aromas of mango and guava in the aqueous fractions, expressed on the unstructured $9 \mathrm{~cm}$ scale. The maximum intensity of the mango aroma in all the trials was observed in the first fraction, with no significant difference between the vacuum and temperature conditions used in the process. It was also found that in all the tests, the samples for the first fraction significantly differed from the samples from the third fraction, indicating that there was a reduction of the volatile compounds as a function of the concentration time. In the experiments carried out at 650 $\mathrm{mmHg}$, the second fraction did not differ significantly from the first one, suggesting that this fraction also carried a considerable amount of volatiles characteristic of the fruit aroma (Table 1). Also, the intensity of the aroma in the two the first fractions was not affected by the increase in process temperature. At $680 \mathrm{mmHg}$, the second fraction did not differ from the first at the operating temperatures of 50 and $65{ }^{\circ} \mathrm{C}$, but at 45 and $55^{\circ} \mathrm{C}$, this behavior was not observed (Table 1).

Considering the concentration of guava juice, the maximum intensity of the fruit aroma was perceived in the first aqueous fraction under all the vacuum and temperature conditions evaluated. At $650 \mathrm{mmHg}$ and 55 and $65^{\circ} \mathrm{C}$, there was a significant reduction of the guava aroma intensity in the second and third fractions collected (Table 1), showing a decrease in the concentration of guava volatiles, dependent on the time of the concentration process. However, at $680 \mathrm{mmHg}$ and 50,55 and $65{ }^{\circ} \mathrm{C}$, the significant difference emerged only in relation to the first fraction, indicating that at the higher vacuum, the volatile carrier was mainly present in this first fraction (Table 1).

The influence of temperature on the aroma intensity characteristic of mango and guava in the first fractions of each assay can best be seen in Fig. 2. The intensity of the characteristic mango aroma was highest at $650 \mathrm{mmHg}$ and $55^{\circ} \mathrm{C}$ (Fig. 2A), and at $680 \mathrm{mmHg}$ at 45 and $55^{\circ} \mathrm{C}$ (Fig. 2B). For guava, the aqueous fraction with the highest fruit aroma intensity also appeared at $55{ }^{\circ} \mathrm{C}$ and $650 \mathrm{mmHg}$ (Fig. 2C). However, when the vacuum was increased $(680 \mathrm{mmHg})$ the aqueous fraction with the highest aroma intensity was obtained at $65{ }^{\circ} \mathrm{C}$, but this difference was not significant (Table 1). Nonetheless, when recovering the aroma of fractions from fruit juice concentration, this information becomes relevant since the higher the quantity of volatiles in the aqueous fraction, the easier it is to try and separate them, by employing other methods.

The results of the sensorial analysis highlighted the importance of the process parameters since for mango juice, the highest intensity of the fruit aroma presented in the first two fractions, and, for guava juice, the first fraction concentrated the characteristic volatiles of the fruit. These findings direct the steps of collecting the volatiles and the subsequent incorporation of the natural aroma of the fruits into juices.

\subsection{Analysis of the Volatile Composition in the Aqueous Fraction}

By examining the composition of each aqueous fraction, the aim was to identify the components present in relatively greater concentration and, possibly, those that play a key role in the characteristic aroma of the fruit. The analysis of the volatiles present in the natural juice was done with the intention of verifying which of the components present in the fruits may have migrated to the aqueous fraction.

Preliminary GC/MS identification of the compounds present in mango and guava juice, respectively, and in the aqueous fractions, as well as the peak areas and retention times of the compounds in the GC/MS Total Ion Chromatogram (TIC) traces, for all the tests, are presented in Tables $\mathbf{2}$ and $\mathbf{3}$, respectively.

Table 2. Trapped compounds from the aqueous fractions obtained under different vacuum and temperature conditions and of natural mango juice.

\begin{tabular}{|c|c|c|c|c|c|c|c|c|c|c|c|}
\hline \multirow{2}{*}{ Peak } & \multirow{2}{*}{$\begin{array}{c}\text { TR } \\
(\mathrm{mim})\end{array}$} & \multirow{2}{*}{ Components } & \multicolumn{8}{|c|}{ Area (\%) } & \multirow{2}{*}{$\mathbf{I K}^{*}$} \\
\hline & & & Natural Juice & 1 & 2 & 3 & 4 & 5 & 6 & 7 & \\
\hline 1 & 3.48 & Isobutylmethylcarbinol & 0.56 & 1.03 & 1.51 & 2.09 & 0.33 & 0.84 & 1.87 & 2.13 & - \\
\hline 2 & 3.75 & $\begin{array}{l}\mathrm{NI} \\
\end{array}$ & 0.49 & 0.45 & 0.73 & 0.39 & 0.32 & 0.39 & 0.13 & 0.11 & - \\
\hline 3 & 4.29 & $\begin{array}{c}\text { cyclohexane, 1,1-2-methyl-1,3- } \\
\text { propanediol-cis }\end{array}$ & 0.44 & 1.17 & 1.28 & 0.80 & 0.62 & 1.36 & 1.01 & 0.42 & 934 \\
\hline 4 & 4.73 & etilbenzene $^{\mathrm{a}}$ & 3.67 & 0.61 & 0.50 & 0.52 & 0.33 & 0.39 & 0.75 & 0.62 & 968 \\
\hline 5 & 4.94 & p-xilene $^{\mathrm{a}}$ & 2.84 & 1.39 & 2.46 & 1.27 & 1.71 & 1.43 & 1.58 & 1.69 & 983 \\
\hline 6 & 5.04 & NI & 0.55 & 0.56 & 0.97 & 0.17 & 0.66 & 0.39 & 0.40 & 0.69 & 990 \\
\hline 7 & 5.48 & Benzene, 1,2-dimethyl & 0.98 & 0.51 & 0.49 & 0.17 & 0.91 & 0.97 & 0.22 & 1.03 & 1022 \\
\hline 8 & 6.11 & NI & 1.08 & 0.25 & 0.24 & 0.90 & 0.60 & 0.79 & 0.47 & 0.57 & 1070 \\
\hline 9 & 6.93 & $\alpha$-pinene & 10.09 & 0.98 & 1.71 & 0.73 & 1.13 & 1.19 & 1.64 & 0.66 & 1129 \\
\hline 10 & 8.12 & $\beta$-pinene & 1.49 & 0.29 & 0.29 & 0.23 & 0.48 & 0.20 & 0.36 & 0.29 & 1216 \\
\hline 11 & 8.66 & $\beta$-mircene & 0.99 & 0.24 & 0.54 & 0.27 & 0.37 & 0.17 & 0.36 & 0.18 & 1259 \\
\hline 12 & 9.02 & $\alpha$-felandren & 0.32 & 0.27 & 0.36 & 0.40 & 0.31 & 0.18 & 0.17 & 0.08 & 1286 \\
\hline
\end{tabular}




\begin{tabular}{|c|c|c|c|c|c|c|c|c|c|c|c|}
\hline \multirow{2}{*}{ Peak } & \multirow{2}{*}{$\begin{array}{c}\text { TR } \\
\text { (mim) }\end{array}$} & \multirow{2}{*}{ Components } & \multicolumn{8}{|c|}{ Area (\%) } & \multirow{2}{*}{$\mathrm{IK}^{*}$} \\
\hline & & & Natural Juice & 1 & 2 & 3 & 4 & 5 & 6 & 7 & \\
\hline 13 & 9.29 & 3-Carene & 52.81 & 4.50 & 7.64 & 2.00 & 2.99 & 6.20 & 4.71 & 2.54 & 1307 \\
\hline 14 & 9.85 & Limonene & 1.42 & 1.35 & 1.32 & 0.37 & 0.51 & 0.72 & 0.78 & 0.29 & 1353 \\
\hline 15 & 10.07 & NI & 0.15 & 0.46 & $\mid 0.16$ & \begin{tabular}{|l|}
0.36 \\
\end{tabular} & 0.26 & 0.25 & 0.33 & 0.06 & 1371 \\
\hline 16 & 10.82 & $\alpha$-terpinene & 0.20 & 0.16 & 0.22 & 1.28 & 0.31 & 0.23 & 0.34 & 0.31 & 1434 \\
\hline 17 & 11.86 & $\gamma$-terpinene & 1.36 & 0.96 & 1.68 & 0.57 & 0.45 & 0.87 & 1.15 & 0.65 & 1524 \\
\hline 18 & 15.34 & NI & 1.12 & 1.18 & 0.30 & 0.80 & 3.81 & 1.30 & 1.63 & 1.22 & 1861 \\
\hline 19 & 16.74 & p-menthyl-1,4-dien-7-ol & 0.26 & 1.13 & 1.06 & 1.90 & 1.85 & 3.19 & 2.25 & 1.47 & 2011 \\
\hline 20 & 17.00 & $\mathrm{NI}$ & 0.13 & 0.53 & 0.49 & 1.33 & 1.01 & 1.61 & 1.22 & 0.79 & 2034 \\
\hline 21 & 17.13 & 2,4-dimethylacetophenone & 0.37 & 1.65 & 1.42 & 2.99 & 1.99 & 4.14 & 3.66 & 2.99 & 2046 \\
\hline 22 & 17.74 & p-ethylacetophenone & 0.24 & 0.82 & 0.82 & 2.16 & 1.16 & 2.28 & 2.09 & 1.76 & 2102 \\
\hline 23 & 18.53 & NI & 0.12 & 0.60 & 0.80 & 0.87 & 0.40 & 0.84 & 0.44 & 0.86 & 2175 \\
\hline 24 & 21.84 & copaeno & 0.19 & 0.97 & 0.52 & 0.30 & 0.71 & 0.61 & 0.35 & 0.24 & 2477 \\
\hline 25 & 23.08 & caryophyllene & 0.08 & 0.19 & 0.08 & 1.10 & 0.14 & 0.21 & 0.17 & 0.05 & - \\
\hline - & - & Total (\%) & 81.75 & 22.25 & 27.59 & 23.97 & 23.36 & 30.75 & 28.08 & 21.7 & - \\
\hline
\end{tabular}

${ }^{a}$ is contaminants; NI is non identified; * is the Kovat Index in capillary collum BPI $(30 \mathrm{~m} \times 0.25 \mathrm{~mm} \times 0.25 \mu \mathrm{m})$.

Table 3. Trapped compounds from the aqueous fractions obtained under different vacuum and temperature conditions and of natural guava juice

\begin{tabular}{|c|c|c|c|c|c|c|c|c|c|c|c|}
\hline \multirow{2}{*}{ Peak } & \multirow{2}{*}{ TR (min) } & \multirow{2}{*}{ Components } & \multicolumn{8}{|c|}{ Area (\%) } & \multirow{2}{*}{ IK* } \\
\hline & & & Natural juice & 1 & 2 & 3 & 4 & 5 & 6 & 7 & \\
\hline 1 & 3.08 & Ethane, 1,1-dietoxi & 3.37 & - & 0.69 & 0.07 & 6.16 & 0.05 & - & 0.67 & 717 \\
\hline 2 & 3.63 & 2 - Hexanone & 0.96 & 2.04 & 2.11 & 1.60 & 3.44 & 2.73 & 3.85 & 2.21 & 761 \\
\hline 3 & 3.79 & n-Hexanal & 31.66 & 11.41 & 37.68 & 39.78 & 11.15 & 35.60 & 26.70 & 20.89 & 771 \\
\hline 4 & 3.90 & 2-Hexanol & 1.53 & 2.26 & 2.71 & 2.02 & 4.29 & 2.80 & 4.44 & 2.82 & 777 \\
\hline 5 & 4.63 & 2-Hexenal, (E)- & 4.77 & 5.96 & 12.33 & 13.93 & 5.29 & 9.65 & 8.03 & 5.87 & 827 \\
\hline 6 & 4.89 & 3-Hexen-1-ol, (Z)- & 0.30 & 2.11 & 1.26 & 2.80 & 4.72 & 0.95 & 0.70 & 2.83 & 836 \\
\hline 7 & 5.21 & 1-Hexanol & 0.77 & 3.40 & 2.21 & 3.93 & 7.06 & 1.88 & 1.93 & 4.16 & 850 \\
\hline 8 & 6.71 & 2(5H)-Furanone, 5-ethyl- & 3.40 & 0.48 & 4.02 & 2.77 & 0.33 & 4.32 & 1.15 & 1.18 & 984 \\
\hline 9 & 8.82 & $\mathrm{NI}$ & 1.04 & 0.39 & 0.53 & 0.46 & 0.15 & 0.53 & 0.26 & 0.26 & - \\
\hline 10 & 9.85 & Eucalyptol & 4.24 & 5.61 & 2.87 & 2.85 & 4.06 & 3.61 & 2.12 & 3.76 & 1020 \\
\hline 11 & 9.96 & NI & 1.35 & 0.19 & 1.26 & 0.91 & 0.18 & 1.53 & 0.41 & 0.43 & - \\
\hline 12 & 10.25 & 1,3,6-Octatriene, 3,7-dimethyl-, (E)- & 11.18 & 0.28 & 0.15 & 0.18 & 0.21 & 0.14 & 0.20 & 0.28 & 1038 \\
\hline 13 & 10.58 & 1,3,7-Octatriene, 3,7-dimethyl- & 0.85 & 0.30 & 0.13 & 0.11 & 0.18 & 0.13 & 0.20 & 0.24 & 1046 \\
\hline 14 & 11.41 & Bicyclo [2.2.1] heptan-2-one, 1,3,3-trimethyl- & 0.71 & 1.98 & 0.61 & 0.53 & 0.72 & 0.65 & 0.65 & 1.20 & 1067 \\
\hline 15 & 13.13 & $\begin{array}{c}\text { Bicyclo [2.2.1] heptan-2one, 1,7,7-trimethyl-, } \\
\text { (1S)- }\end{array}$ & 0.55 & 1.75 & 0.50 & 0.45 & 0.58 & 0.61 & 0.48 & 0.90 & 1146 \\
\hline 16 & 13.65 & Benzaldehyde, 4-ethyl- & 0.64 & 1.68 & 1.12 & 1.00 & 1.86 & 1.35 & 1.91 & 1.89 & 1169 \\
\hline 17 & 16.75 & $\begin{array}{l}\text { 1,4-Cyclohexadiene-1-methanol, 4-(1- } \\
\text { methylethyl)- }\end{array}$ & 2.75 & 7.70 & 4.75 & 3.74 & 8.43 & 5.54 & 8.55 & 7.12 & 1261 \\
\hline 18 & 17.02 & 4-(1-Hidroxyethyl)benzaldehyde & 1.48 & 3.91 & 2.62 & 1.98 & 4.30 & 2.85 & 4.71 & 3.61 & 1291 \\
\hline 19 & 17.12 & 3,4-Dimethylacetophenone & 2.86 & 8.86 & 4.95 & 3.99 & 8.79 & 6.17 & 8.84 & 7.43 & - \\
\hline 20 & 17.72 & 2,5-Dimethylacetophenone & 1.69 & 5.09 & 2.89 & 2.32 & 5.00 & 3.52 & 5.24 & 4.27 & - \\
\hline 21 & 21.78 & NI & 0.37 & 0.80 & 0.23 & 0.23 & 0.35 & 0.25 & 0.26 & 0.51 & - \\
\hline 22 & 23.04 & $\beta$-Caryophyllene & 6.09 & 0.69 & 0.15 & 0.15 & 0.35 & 0.25 & 0.38 & 0.45 & 1396 \\
\hline 23 & 23.35 & NI & 0.35 & 1.12 & 0.67 & 0.52 & 0.96 & 0.78 & 1.25 & 0.86 & - \\
\hline 24 & 24.04 & $\alpha$-Caryophyllene & 0.59 & 0.50 & 0.26 & 0.21 & 0.43 & 0.41 & 0.46 & 0.24 & 1449 \\
\hline 25 & 24.99 & $\begin{array}{l}\text { Naphthalene, decahydro-1,6-bis(methylene)-4- } \\
\text { (1-methylethyl)-, }(4 \alpha, 4 \mathrm{a} \alpha, 8 \mathrm{a} \alpha) \text { - }\end{array}$ & 0.32 & 0.23 & - & 0.07 & 0.06 & - & 0.10 & 0.18 & 1457 \\
\hline 26 & 25.31 & $\begin{array}{c}\text { Naphthalene, } 1,2,3,4,4 \mathrm{a}, 5,6,8 \mathrm{a}-\text { octahydro-4a,8- } \\
\text { dimethyl-2-(1-methylethenyl)-, [2r- } \\
(2 \alpha, 4 \mathrm{a} \alpha, 8 \mathrm{a} \beta)]-\end{array}$ & 1.80 & 0.22 & 0.07 & 0.07 & - & 0.07 & 0.07 & - & 1467 \\
\hline 27 & 25.80 & $\begin{array}{c}\text { Naphthalene, } 1,2,3,5,6,7,8,8 \mathrm{a} \text {-octahydro-1,8a- } \\
\text { dimethyl-7-(1-methylethenyl)-, [1 s- } \\
(1 \alpha, 7 \alpha, 8 \mathrm{a} \alpha)]-\end{array}$ & 2.02 & 0.21 & 0.06 & 0.06 & 0.09 & 0.07 & 0.06 & 0.16 & 1486 \\
\hline 28 & 27.54 & 3-Heptadecen-5-yne, (Z)- & 0.72 & 1.93 & 0.49 & 0.41 & 0.26 & 0.13 & 0.08 & 0.70 & - \\
\hline- & - & Total $(\%)$ & 88.36 & 71.10 & 87.32 & 87.14 & 79.40 & 86.57 & 83.03 & 75.12 & - \\
\hline
\end{tabular}




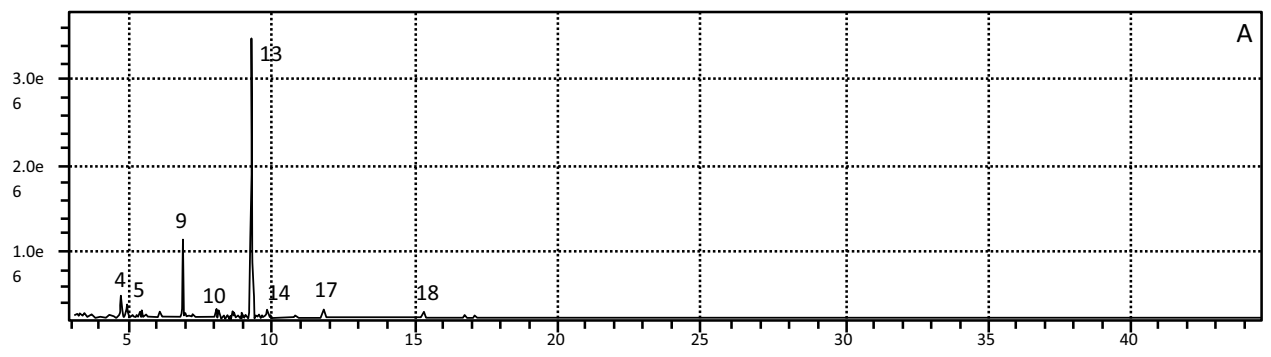

B
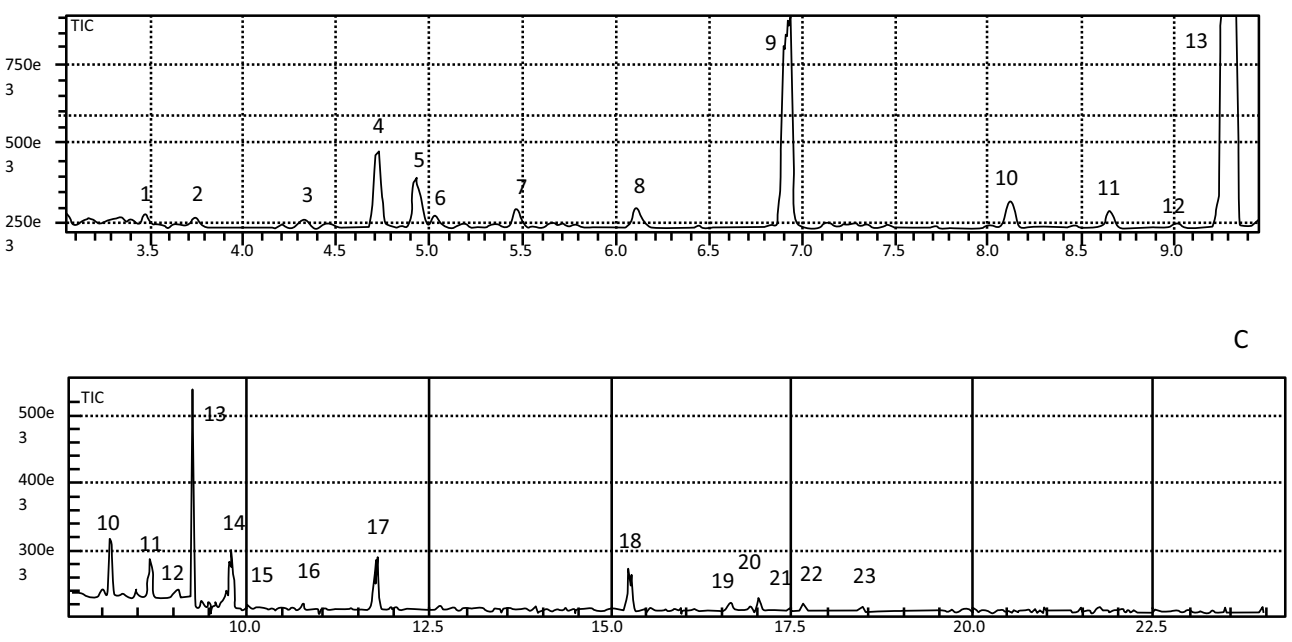

Fig. (4). Total Ion Chromatogram (TIC) for the aqueous phase of natural mango juice (A), enlargement of peaks 1 to 13 (B); enlargement of the peaks from 10 to $25(\mathrm{C})$.
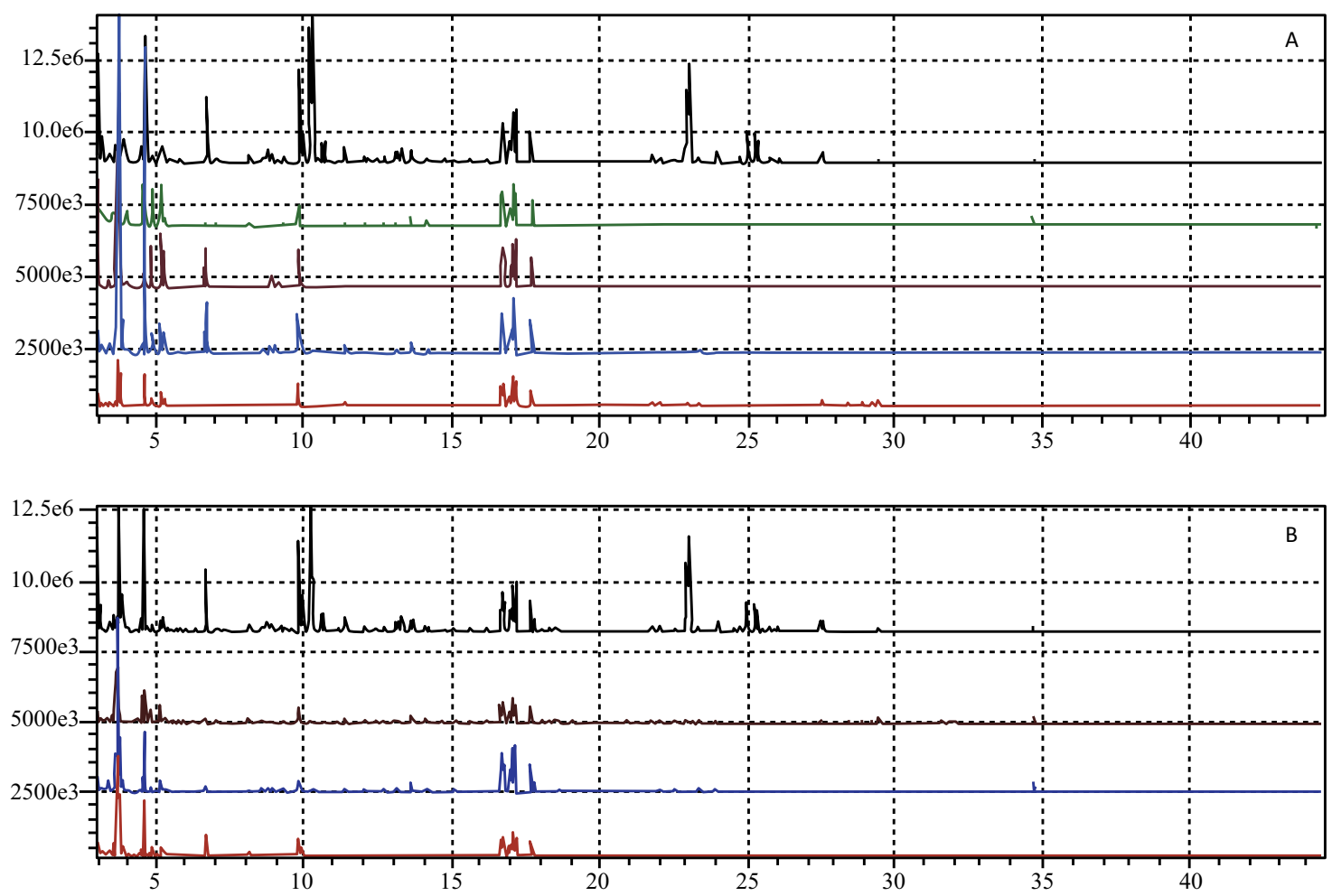

Fig. (5). Chromatogram of total ions (TIC) of natural juice - with the TICs of the assays $1-, 2-, 3-, 4-$ (A) and TIC of the natural juice with the TIC of the assays $5-, 6-, 7-(\mathrm{B})$. 

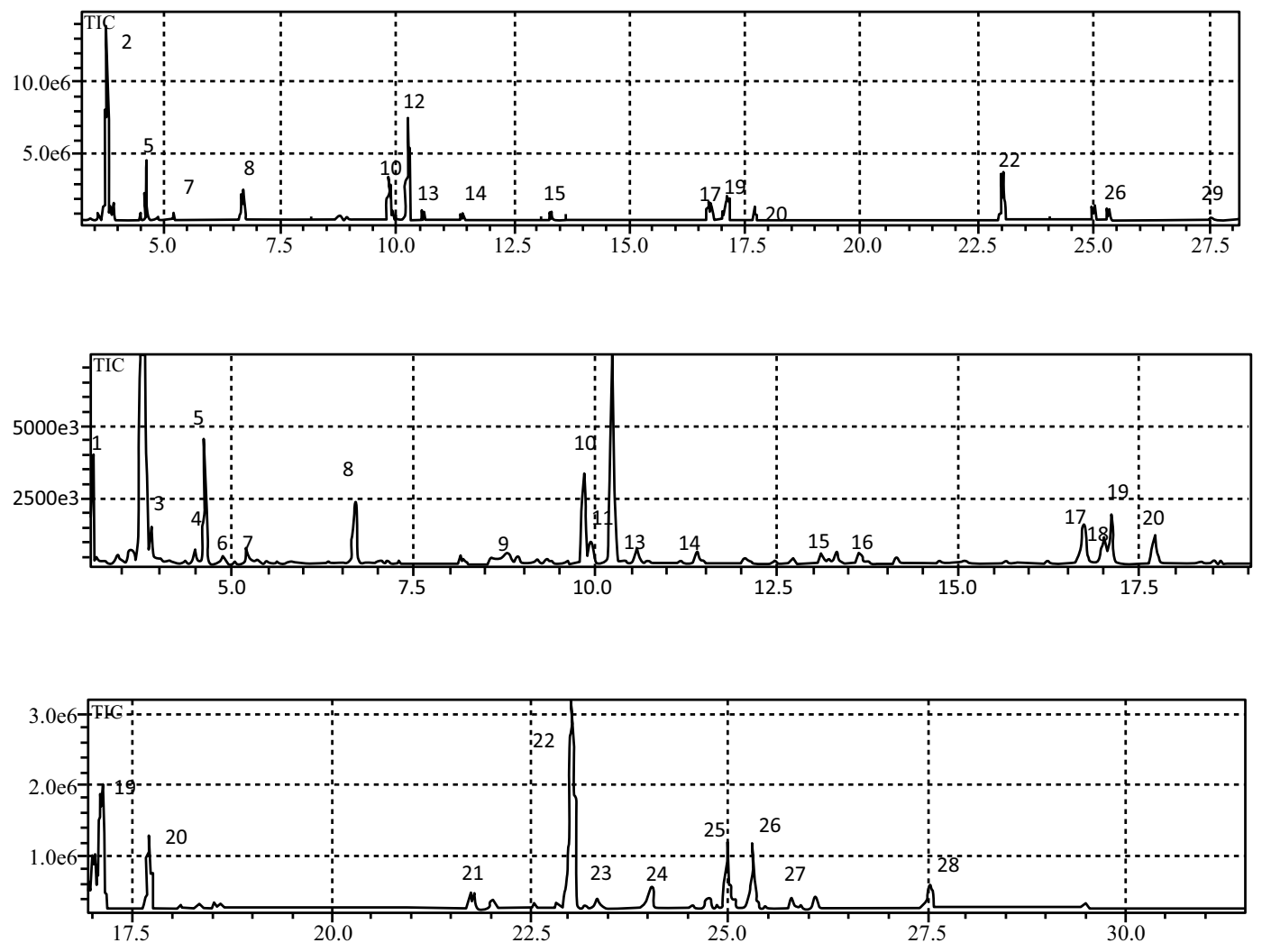

Fig. (6). Total Ions Chromatogram (TIC) for the aqueous phase of natural guava juice (A) enlargement of peaks 1 to 20; (B) enlargement of peaks 19 to 28 .

\subsubsection{Mango}

(Fig. 3A) compares the TIC of the natural mango juice with that of the aqueous fractions from the concentration assays, under the different operating conditions. In the amplification presented, it seemed most of the compounds present in the natural juice were not in the aqueous fractions (Figs. 3B and 3C). However, when integrating the peaks, it was evident that the components present in the natural juice were also present in these fractions, albeit at lower intensity when comparing the area percentages of the peaks with those of the juice (Table 2).

$\alpha$-Pinene and 3-carene were the major components of both the natural juice and the aqueous fractions, with retention times of 6.93 and $9.29 \mathrm{~min}$, respectively, (Fig. 3). For a better visualization of the TIC, (Fig. 4) displays each of the peaks on a magnified scale.

The components observed between peaks 4 and 8 may be related to contaminants of the solvent, despite its chromatographic grade (Fig. 4). Peak 9 confirmed the presence of the monoterpenes $\alpha$ - and $\beta$-pinene, $\beta$-myrcene, $\alpha$-phellandrene, 3 carene, limonene, and $\gamma$ - and $\alpha$-terpinene, which are characteristic of volatiles present in mangoes of several species [28 - 30]. According to Bender et al. [28], 3-carene is the main monoterpene present in Tommy Atkins mango, as also evidenced in the current work. Two ketones (peaks 21 and 22) and two sesquiterpenes (peaks 24 and 25) were also noted (Table 2).

The percentage of the total relative area of the peaks listed in Table $\mathbf{2}$ for the volatiles identified in the natural mango juice represented approximately $82 \%$ of the total components present. The sum of the percentage of these areas in the aqueous fraction fell considerably to between $\sim 22$ and $31 \%$.

Considering only the percentage of the relative area of the peaks, since the concentration was not determined, it was noticed that the main components in the natural mango juice complemented those in the aqueous fractions. Among these constituents, were the monoterpenes, 3 -carene, $\alpha$-pinene, $\gamma$ terpinene and limonene. The data also revealed a considerable increase in the intensity of the ketone peaks (21 and 22) in the aqueous fraction. Considering that these compounds have higher molecular weight than monoterpenes, and if all volatiles have lowered boiling temperatures at reduced pressures, these ketones are proposed to be volatiles derived from the degradation of some component present in the juice during the concentration (Table 2).

Pandit et al. [16] characterized the major chemical classes in mango as alcohols, aldehydes, monoterpene hydrocarbons, oxygenated monoterpenes, sesquiterpene hydrocarbons, oxygenated sesquiterpenes, lactones, ketones and non-terpene hydrocarbons. In a study conducted by San et al. [31], the main volatile aroma compounds in the ripe fruit of two different mango varieties (B74 and Kensington Pride) were detected at mean concentrations $(\mu \mathrm{g} / \mathrm{L})$ of 0.6 and 0.5 (ethylene octanoate), 6 and 54 (hexanal), 12 and 14 ( $p$-cymene), 23 and $43(\alpha-$ terpinene), 29 and 31 (2-carene), 216 and 264 (limonene), 929 
Table 4. Vitamin $\mathrm{C}$ present in mango and guava juices before and after concentration and its loss percentage at each assay.

\begin{tabular}{|c|c|c|c|c|c|c|c|c|c|}
\hline \multirow[t]{2}{*}{ Assay } & \multirow{2}{*}{$\begin{array}{l}\text { Vacuum } \\
(\mathrm{mmHg})\end{array}$} & \multirow{2}{*}{$\begin{array}{c}\mathrm{T} \\
\left({ }^{\circ} \mathrm{C}\right)\end{array}$} & \multirow{2}{*}{$\begin{array}{c}\text { Time } \\
(\text { mim })\end{array}$} & \multicolumn{3}{|c|}{$\begin{array}{c}\text { Vit. } C^{*} \text { (mango) } \\
\text { (mg ascorbic acid/100 mL juice) }\end{array}$} & \multicolumn{3}{|c|}{$\begin{array}{c}\text { Vit } C^{*} \text { (guava) } \\
\text { (mg ascorbic acid } / 100 \mathrm{~mL} \text { juice) }\end{array}$} \\
\hline & & & & Initial & Last & \% Loss & Initial & Last & \% Loss \\
\hline 1 & 650 & 50 & 45 & $0.30 \pm 0.01$ & $0.19 \pm 0.01$ & 34.99 & $27.99 \pm 2.97$ & $23.79 \pm 5.94$ & 15.01 \\
\hline 2 & 650 & 55 & 45 & $0.47 \pm 0.01$ & $0.23 \pm 0.01$ & 51.60 & $24.84 \pm 3.63$ & $18.84 \pm 2.42$ & 24.15 \\
\hline 3 & 650 & 65 & 45 & $0.53 \pm 0.12$ & $0.20 \pm 0.02$ & 62.86 & $37.83 \pm 1.98$ & $23.82 \pm 0.99$ & 37.04 \\
\hline 4 & 680 & 45 & 60 & $0.75 \pm 0.14$ & $0.38 \pm 0.02$ & 49.80 & $40.44 \pm 5.20$ & $33.82 \pm 4.17$ & 16.37 \\
\hline 5 & 680 & 50 & 45 & $0.72 \pm 0.03$ & $0.25 \pm 0.02$ & 65.91 & $36.75 \pm 4.16$ & $27.92 \pm 6.24$ & 24.03 \\
\hline 6 & 680 & 55 & 45 & $0.65 \pm 0.00$ & $0.15 \pm 0.01$ & 77.28 & $53.81 \pm 5.07$ & $32.3 \pm 5.07$ & 39.98 \\
\hline 7 & 680 & 65 & 30 & $0.65 \pm 0.01$ & $0.15 \pm 0.01$ & 77.28 & $56.22 \pm 4.07$ & $25.22 \pm 5.10$ & 55.14 \\
\hline
\end{tabular}

* Juice diluted at $4{ }^{\circ}$ Brix for all assays.

and 383 (3-carene), and 11,272 and 19,719 ( $\alpha$-terpinolene), respectively. Furthermore, $\alpha$-terpinolene, 3 -carene, $p$-cymene and limonene were demonstrated to be odor-active volatiles in all the mangoes studied, and $\alpha$-terpinolene, 3 -carene and hexanal were the most odor-active.

Benevides et al. [32] determined the volatile compounds in three mango varieties (Tommy Atkins, Rosa and Espada) and found that the main classes of compounds were esters and terpenes. Among the identified compounds, only $\alpha$-pinene, $\beta$ myrcene and caryophyllene were common to all three varieties. The relative abundance of the volatile organic compounds varied among the samples of the three varieties. For instance, ethyl butanoate ( $17.7 \%$ relative abundance) was recorded only in the Tommy Atkins mango. 3-Carene was detected in the Tommy Atkins (51\% relative abundance) and Espada (17\% relative abundance) varieties but not Rosa, and the relative amounts of $\alpha$-pinene were $2.8 \%$ (Espada), $17.9 \%$ (Tommy Atkins) and $31.3 \%$ (Rosa).

\subsubsection{Guava}

(Fig. 5) compares the TIC of the natural guava juice with those of the aqueous fractions from trials, 2,3 and 4 (Fig. 5A), and 5, 6 and 7 (Fig. 5B). Only when viewing the integrated peaks of the TIC (Table 3), was it apparent that the compounds present in the natural juice also appeared in these fractions, albeit at lower intensity when comparing the peak area percentages. According to the TIC of the aqueous fractions collected in the tests (Figs. 4 and 5), the most abundant volatile compounds were common to all the samples.

To better illustrate the preliminary identification of the compounds detected in guava juice and their correlation with the compounds found in the obtained aqueous fractions, Fig. 6 shows the augmented TIC of guava juice. The GC/MS identification of the compounds corresponding to each of these numbered peaks, the area percentage of the same compounds in all assays, their respective retention times and their Kovats indices, are shown in Table $\mathbf{3}$.

Among the volatiles present in both the juice and aqueous fractions, carbonyl compounds, alcohols, sesquiterpenes, esters and ketones, all characteristic of the volatiles known to occur in various guava species, were observed [33 - 35].

As seen in the mango analysis, the compounds abundant in high proportions in the guava juice, such as $n$-hexanal or eucalyptol, also migrated at high proportions into the aqueous fractions. Other volatiles, such as (E)-2-hexenal, (Z)-3hexen-1-ol, 1-hexanol, 3,4-dimethylacetophenone and 2,5dimethylacetophenone were noted in higher proportions in the aqueous than juice fraction, demonstrating that such compounds are entrained within the water vapor and thereby enriched in the aqueous fraction. If these volatiles are key components in the constitution of the juice aroma, any decrease in their quantities during concentration of the juice will impair its flavor (taste and odor).

Interestingly, the sesquiterpenes, such as $\beta$ - and $\gamma$-caryophyllene, important in the characterization of tropical fruit flavor, migrated to the aqueous fraction, but were detected in smaller proportions than those present in the original juice. The relative percentage of the total peaks (Table 3) for the volatiles detected in the natural juice of guava, represented about $89 \%$ of the total volatiles captured on Porapak-Q. The sum of the percentage of these areas in the aqueous fraction remained close, at approximately $71-88 \%$. Considering only the percentages of the relative areas of the peaks, since the concentration was not determined, it was confirmed that the components found in greater intensity in the natural juice of guava correlated with those found in the aqueous fractions.

Soares et al. [8] found the esters cis-3-hexenyl acetate $(21.78 \%)$ and trans-3-hexenyl acetate $(17.80 \%)$ were the most abundant in mature white guavas ( $P$. guajava) of cultivar Cortibel. Other important compounds were the sesquiterpenes caryophyllene $(12.96 \%), \alpha$-humulene $(7.85 \%)$ and $\beta$-bisabolene (5.46\%). Moon et al. [36] observed that hexane, (E)-2hexenal and $(E)$-caryophyllene, were common at all maturation stages of guavas analyzed, and (Z)-3-hexenyl acetate, ethyl butanoate and ethyl octanoate predominated in mature guavas.

\subsection{Changes in Vitamin $C$ Content}

The guava juice had considerably more vitamin $\mathrm{C}$ than the Tommy Atkins mango juice (Table 4). Owing to the thermal sensitivity of vitamin $\mathrm{C}$, all the concentrated juice samples displayed vitamin $\mathrm{C}$ losses, with decreases varying between 35 and $77 \%$ for mango and 15 to $55 \%$ for guava. The losses were accentuated as a function of the increase in operating temperature and vacuum (Table 4). The concentrated mango and guava juices obtained in this work, which had a soluble solids content of $11^{\circ} \mathrm{Brix}$ (equivalent to commercial juice concentrates), presented an average value of $1.5 \pm 0.7$ and 
$109 \pm 12 \mathrm{mg}$ ascorbic acid/100 mL mango and guava juices, respectively. Fruit juices marketed with a soluble solids level of around $11^{\circ}$ Brix contain about $100 \mathrm{mg}$ ascorbic acid $/ 100 \mathrm{~mL}$ juice, suggesting that the mango juice concentrate in its reconstitution would have to be enriched with ascorbic acid, unlike guava juice.

Besides displaying a relatively greater concentration of vitamin $\mathrm{C}$ compared to mango juice, the loss of this vitamin as a function of the concentration process was lower in the guava juice (Table 4).

\section{CONCLUSION}

It was possible to verify that the samples of the aqueous fractions from the first collection, up to $30 \mathrm{~min}$ of concentration, mainly contribute to the characteristic volatiles of the fruit aroma. This observation is technically truly relevant because it is interesting that only the aqueous fractions collected at the beginning of juice concentrations are applied with the specific purpose of improving the aroma of the beverage, enriching it with the natural aroma characteristic of the fruit. Also, in the processes of separating these volatiles from the aqueous fraction, the more concentrated the constituents, the easier the attempt to separate them.

GC/MS identification of the compounds indicated that the major components present in the fresh fruits are present into the aqueous fraction. In addition to this finding, the sensorial analyses of these fractions verified that these components play an important role in the intensity of the characteristic odor of the fruits since the intensity evaluated on the unstructured $9 \mathrm{~cm}$ scale resulted in values above five for these first fractions, independently of the fruit.

With the technique employed in this work, 16 volatile compounds in the juice and aqueous fraction of mango, and 24 volatiles in the aqueous fraction of guava juice were identified.

The concentration of vitamin $\mathrm{C}$ decreased as the temperature used in the juice concentration process increased. It is noteworthy that the loss of vitamin $\mathrm{C}$ was higher for the mango juice, which had a relatively lower initial concentration of vitamin $\mathrm{C}$ than guava juice.

\section{ETHICS APPROVAL AND CONSENT TO PARTI- CIPATE}

This study used humans as a measuring instrument. The people performed the sensorial analyzes in agreement with the National Council of Ethics in Research (CONEP) of the Ministry of Health of Brazil, having been registered with FR-120397 and duly approved by the Research Ethics Committee of the Nursing School of Ribeirão Preto, University of São Paulo (Protocol 0766/2007).

\section{HUMAN AND ANIMAL RIGHTS}

No animals/humans were used for studies that are the basis of this research.

\section{CONSENT FOR PUBLICATION}

Not applicable.

\section{CONFLICT OF INTEREST}

The authors declare no conflict of interest, financial or otherwise.

\section{ACKNOWLEDGEMENTS}

We would like to acknowledge Fundação de Amparo à Pesquisa do Estado de São Paulo (FAPESP), Process $\mathrm{n}^{\circ}$ 06/05897-5 for the study fellowship, and Process $\mathrm{n}^{\circ}$ $05 / 53095-2$, a thematic project that provided the means for the development of this work.

\section{REFERENCES}

[1] Damodaran S, Parkin KL, Fennema OR. Química de Alimentos. Porto Alegre. Art Med 2010; 900 .

[2] Cassano A, Jiao B, Drioli E. Production of concentraed kiwifruit juice by integrated membrane process. Food Res Int 2004; 37(2): 139-48. membrane process

[3] Branco IG, Sanjinez-Argandoña EJ, Silva MM, Paula TM. Sensorial evaluation and physical-chemical stability of a blend of orange and carrot. Food Sci Technol 2007; 27(1): 7-12 [http://dx.doi.org/10.1590/S0101-20612007000100002]

[4] Qi R, Jiang H, Nian M, Yan Z. Mathematical modeling and simulation of countercurrent multiple effect evaporation for fruit juice concentration. J Food Eng 2015; 146: 243-51.

[http://dx.doi.org/10.1016/j.jfoodeng.2014.09.015]

[5] Pereira CC, Rufino JRM, Habert AC, Nobrega R, Cabral LMC, Borges CP. Aroma compounds recovery of tropical fruit juice by pervaporation membrane material selection and process evaluation. $\mathrm{J}$ Food Eng 2005; 66(1): 77-87.

[http://dx.doi.org/10.1016/j.jfoodeng.2004.02.037]

[6] Yanniotis S, Tsitziloni K, Dendrinos G, Mallouchos A. Aroma recovery by combining distillation with absorption. J Food Eng 2007; 78(3): 882-7.

[http://dx.doi.org/10.1016/j.jfoodeng.2005.11.028]

[7] Cardello HMAB, Cardello L. Teor de vitamina C, atividade de ascorbato oxidase e perfil sensorial de manga (Mangífera indica L.) Variação Haden, durante o amadurecimento. Food Sci Technol (Campinas) $1998 ; 18(2):$ 211-7.

[http://dx.doi.org/10.1590/S0101-20611998000200013]

[8] Soares FD, Pereira T, Marques MOM, Monteiro AR. Volatile and nonvolatile chemical composition of the white guavafruit (Psidium guajava) at different stages of maturity. Food Chem 2007; 100(1): $15-21$

[http://dx.doi.org/10.1016/j.foodchem.2005.07.061]

[9] Thaipong K, Boonprakob U, Crosby K, Cisneros-Zevallos L, Byrne DH. Comparison of ABTS, DPPH, FRAP, and ORAC assays for estimating antioxidant activity from guava fruit extracts. J Food Compos Anal 2006; 19: 669-75.

[http://dx.doi.org/10.1016/j.jfca.2006.01.003]

[10] Bomben JL, Bruin S, Thijssen HAC, Merson RL. Aroma recovery and retention in concentration and drying of foods. Adv Food Res 1973; 20: $1-111$.

[http://dx.doi.org/10.1016/S0065-2628(08)60191-3]

[11] Riu-Aumatell M, Castellari M, Lópes-Tamames E, Galassi S, Buxaderas S. Characterisation of volatile compounds of fruit juices and nectars by HS/SPME and GC/MS. Food Chem 2004; 87(4): 627-37.

[http://dx.doi.org/10.1016/j.foodchem.2003.12.033]

[12] Olsson J, Trägårdh G. Influence of feedflow velocity on pervaporative aroma recovery from a model solution of apple juice aroma compounds. J Food Eng 1999; 39(1): 107-15.

[http://dx.doi.org/10.1016/S0260-8774(98)00154-X]

[13] Macleod AJ, Pieris NM. Comparison of the volatile components of some mango cultivars. Phytochemistry 1984; 23(2): 361-6. [http://dx.doi.org/10.1016/S0031-9422(00)80333-7]

[14] MacLeod AJ, Snyder CH. Volatile components of two cultivars of mango from Florida. J Agric Food Chem 1985; 33(3): 380-4. [http://dx.doi.org/10.1021/jf00063a015]

[15] Sakho M, Chassagne D, Jaus A, Chiarazzo E, Crouzet J. Enzymatic maceration: Effects on volatile components of mango pulp. J Food Sci 1998; 63(6): 975-8.

[http://dx.doi.org/10.1111/j.1365-2621.1998.tb15836.x] 
[16] Pandit SS, Chidley HG, Kulkarni RS, Pujari KH, Giri AP, Gupta VS. Cultivar relationships in mango based on fruit volatile profiles. Food Chem 2009; 114(1): 363-72

[http://dx.doi.org/10.1016/j.foodchem.2008.09.107]

[17] Gill KS. Guavas.Encyclopedia of Food and Health. 2016; pp. 270-77.

[18] Joseph B, Mini P. Review on nutritional, medicinal and pharmacological properties of guava (Psidium guajava Linn.). Int J Pharma Bio Sci 2011; 2(1): 53-69.

[19] Ramteke RS, Eipeson WE, Patwardhan MV. Behaviour of aroma volatiles during the evaporative concentration of some tropical fruit juices and pulps. J Sci Food Agric 1990; 50(3): 399-405.

[http://dx.doi.org/10.1002/jsfa.2740500312]

[20] Karlsson HOE, Trägardh G. Aroma recovery during beverage processing. J Food Eng 1997; 34(2): 159-78.

[http://dx.doi.org/10.1016/S0260-8774(97)00081-2]

[21] Dawiec-Lisniewska A, Pdstawczyk D, Witek-Krowiak A. Concentration of juice aroma compound from model multicomponent solution and natural apple juice hydrolate: Optimization and modeling by design of experiment. J Food Process Eng 2018; 41: 1-10. [http://dx.doi.org/10.1111/jfpe.12669]

[22] Dawiec-Liśniewska A, Szumny A, Podstawczyk D, Witek-Krowiak A. Concentration of natural aroma compounds from fruit juice hydrolates by pervaporation in laboratory and semi-technical scale. Part 1. Base study. Food Chem 2018; 258: 63-70.

[http://dx.doi.org/10.1016/j.foodchem.2018.03.023] [PMID: 2965 5755]

[23] Zenebon O, Pascuet NS, Tiglea P. Métodos físico-químicos para análise de alimentos. 4 ed, 1ed digital. São Paulo: Instituto Adolfo Lutz 2008; p. 1020. http://www.ial.sp.gov.br/resources/editorinplace /ial/2016_3_19/analisedealimentosial_2008.pdf?attach=true

[24] Meilgaard M, Civille GV, Carr BT. Sensory Evaluation Techiniques. Boca Raton: CRC Press 1988; p. 281.

[25] Stone H, Sidell JL. Sensory Evaluation Practices. Orlando: Academic Press 1985 ; p. 310

[26] Franco MRB, Rodrigues-Amaya DB. Trapping of Soursop (Annona muricata) Juice Volatiles on Porapak Q by Suction. J Sci Food Agric 1983; 34(3): 293-9.

[http://dx.doi.org/10.1002/jsfa.2740340313]

[27] Oliveira AL, Lopes RB, Cabral FA, Eberlin MN. Volatile compounds from pitanga frit (Eugenia uniflora L.). Food Chem 2006; 99(1): 1-5. [http://dx.doi.org/10.1016/j.foodchem.2005.07.012]

[28] Bender RJ, Brecht JK. Aroma volatiles of mature-green and tree-ripe
"Tommy Atkins" mangoes after controlled atmosphere $v s$. air storage. HortScience 2000; 35(4): 684-6.

[http://dx.doi.org/10.21273/HORTSCI.35.4.684]

[29] Lalel HJD, Singh Z, Tan SC. Distribution of aroma volatile compounds in different parts of mango fruit. J Hortic Sci Biotechnol 2003; 78(2): 131-8.

[http://dx.doi.org/10.1080/14620316.2003.11511595]

[30] Pino JA, Mesa J, Muñoz Y, Martí MP, Marbot R. Volatile components from mango (Mangifera indica L.) cultivars. J Agric Food Chem 2005; 53(6): 2213-23.

[http://dx.doi.org/10.1021/jf0402633] [PMID: 15769159]

[31] San AT, Joyce DC, Hofman PJ, et al. Stable isotope dilution assay (SIDA) and HS-SPME-GCMS quantification of key aroma volatiles for fruit and sap of Australian mango cultivars. Food Chem 2017; 221: 613-9.

[http://dx.doi.org/10.1016/j.foodchem.2016.11.130] [PMID: 2797 9249]

[32] Benevides CMJ, Bezerra MA, Pereira PAP, Andrade JB. HSSPME/GC-MS analysis of VOC and multivariate techniques applied to the discrimination of Brazilian varieties of mango. Am J Anal Chem 2014; 5(3): 157-64.

[http://dx.doi.org/10.4236/ajac.2014.53019]

[33] Jordán MJ, Margaría CA, Shaw PE, Goodner KL. Volatile components and aroma active compounds in aqueous essence and fresh pink guava fruit puree (Psidium guajava L.) by GC-MS and multidimensional GC/GC-O. J Agric Food Chem 2003; 51(5): 1421-6. [http://dx.doi.org/10.1021/jf0207651] [PMID: 12590492]

[34] Steinhaus M, Sinuco D, Polster J, Osorio C, Schieberle P. Characterization of the aroma-active compounds in pink guava (Psidium guajava, L.) by application of the aroma extract dilution analysis. J Agric Food Chem 2008; 56(11): 4120-7.

[http://dx.doi.org/10.1021/jf8005245] [PMID: 18476695]

[35] Yen GC, Lin HT. Changes in volatile flavor components of guava juice with high-pressure treatment and heat processing and during storage. J Agric Food Chem 1999; 47(5): 2082-7.

[http://dx.doi.org/10.1021/jf9810057] [PMID: 10552500]

[36] Moon P, Fu Y, Bai J, Plotto A, Crane J, Chambers A. Assessment of fruit aroma for twenty-seven guava (Psidium guajava) accessions through three fruit developmental stages. Sci Hortic (Amsterdam) 2018; 238: 375-83.

[http://dx.doi.org/10.1016/j.scienta.2018.04.067]

\section{(C) 2019 Bodini et al}

This is an open access article distributed under the terms of the Creative Commons Attribution 4.0 International Public License (CC-BY 4.0), a copy of which is available at: https://creativecommons.org/licenses/by/4.0/legalcode. This license permits unrestricted use, distribution, and reproduction in any medium, provided the original author and source are credited. 